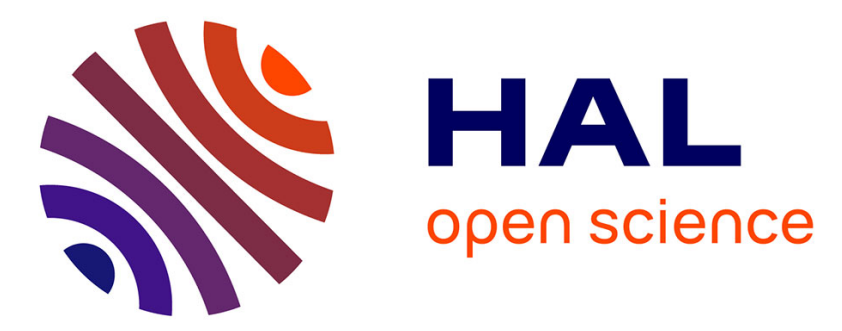

\title{
Influence of process-induced microstructure on hardness of two Al-Si alloys
}

Shadan Tabibian, Eric Charkaluk, Andrei Constantinescu, Gildas Guillemot, Fabien Szmytka

\section{> To cite this version:}

Shadan Tabibian, Eric Charkaluk, Andrei Constantinescu, Gildas Guillemot, Fabien Szmytka. Influence of process-induced microstructure on hardness of two Al-Si alloys. Materials Science and Engineering: A, 2015, 646, pp.190-200. 10.1016/j.msea.2015.08.051 . hal-01253000

HAL Id: hal-01253000

https://hal-mines-paristech.archives-ouvertes.fr/hal-01253000

Submitted on 1 Jun 2021

HAL is a multi-disciplinary open access archive for the deposit and dissemination of scientific research documents, whether they are published or not. The documents may come from teaching and research institutions in France or abroad, or from public or private research centers.
L'archive ouverte pluridisciplinaire HAL, est destinée au dépôt et à la diffusion de documents scientifiques de niveau recherche, publiés ou non, émanant des établissements d'enseignement et de recherche français ou étrangers, des laboratoires publics ou privés.

\section{(c)(1)}

Distributed under a Creative Commons Attribution| 4.0 International License 


\title{
Influence of process-induced microstructure on hardness of two Al-Si alloys
}

\author{
Shadan Tabibian ${ }^{\mathrm{a}, \mathrm{b}, \mathrm{c}}$, Eric Charkaluk ${ }^{\mathrm{b}}$, Andrei Constantinescu ${ }^{\mathrm{c}}$, Gildas Guillemot ${ }^{\mathrm{b}}$, \\ Fabien Szmytka ${ }^{\text {a,* }}$
}

\footnotetext{
${ }^{a}$ Automotive Research and Innovation Division - PSA Peugeot Citroën, Route de Gisy-Vélizy-Villacoublay 78943, France ${ }^{b}$ LML, Laboratoire Mécanique de Lille, Ecole Centrale de Lille - Ecole Nationale Superieure des Arts et Metiers, Cité Scientifique, 59650 Villeneuve d'Ascq, France ${ }^{c}$ LMS, Laboratoire Mécanique Solides, Ecole Polytechnique, Route Saclay, 91120 Palaiseau, France
}

\begin{abstract}
This paper analyses the influence of thermal-induced aging on the strength of cast A319 and A356 aluminum alloys. This phenomena is of primary importance especially in the automotive industry, where on one hand the alloys experience Thermo-Mechanical and Low Cycle Fatigue loading conditions and on the other hand their microstructure is induced both by the manufacturing process and the thermal histories. The alloys studied here were produced using an industrial Lost Foam Casting process which affects significantly the microstructure and the precipitation compared to standard Die Casting process. The paper compares mechanical properties of these peculiar alloys in terms of microhardness at the macroscopic level as a function of thermal overaging time and at the microscopic level in terms of properties of the different phases (intermetallics, eutectics) present in the microstructure. Important differences can be observed between these different phases and the results are consistent with similar studies from the literature on different aluminum alloys and processes.
\end{abstract}

\section{Introduction}

Thermo-Mechanical Fatigue (TMF) of cylinder head fire decks is nowadays a critical design aspect in the automotive industry as a consequence of new constraints imposed by fuel efficiency, engine performances and polluting emission reduction. From a material point of view, this application experiences operating temperatures up to $250{ }^{\circ} \mathrm{C}$ which are very high for the aluminum alloys commonly used for the manufacturing of these parts. The alloy indeed locally reaches $50-70 \%$ of its melting temperatures and exceeds the maximal temperatures of the heat treatments that could be used for the stabilization of its microstructure (T7 for instance). Moreover, these operating temperatures induce plasticity, creep and ageing effects which need to be considered in a durability assessment of the structure [1].

Until now, gravity Die Casting (DC) with permanent dies has been the common choice for the manufacturing of the cylinder head. For some years now, the Lost Foam Casting (LFC) process has become a new standard manufacturing process as it enables the realization of intricate parts with an excellent surface finish and an

\footnotetext{
* Corresponding author.

E-mail address: fabien.szmytka@mpsa.com (F. Szmytka).
}

important cost reduction due to the suppression of the expensive metallic molds and the decrease of the energetic costs. The LFC process has however some drawbacks, when compared to DC. It shows a low solidification rate and consequently produces a coarser microstructure expressed in terms of grain size and SDAS (Secondary Dendrite Arm Spacing), with numerous intermetallic and eutectic phases and residual porosity formed during the degradation of the polymeric pattern $[2,3]$.

The ductility of casting alloys is usually low, and changes in the casting process as well as changes in the chemical composition and/or heat treatment which aimed at improving some properties, can sometimes decrease the material strength for structural applications. Therefore it is important to assess the effect of changes in the microstructure both on the ductility and the strength of the material [4]. Previous investigations have shown that, besides the grain size and the grain boundaries, other important metallurgic factors that significantly affect the ductile fracture of aluminum alloys are second phase particles inherently contained in the alloys, including large $\mathrm{Fe}, \mathrm{Cu}$, and Si-rich inclusions (about 1-10 $\mu \mathrm{m}$ in diameter), intermediate $\mathrm{Cr}$, $\mathrm{Mn}$, or $\mathrm{Zr}$-rich dispersoids (about $0.05-0.5 \mu \mathrm{m}$ in diameter), and small precipitates (nanometer size). The large particles, defined as constituents, are brittle in nature and are usually the primary void/crack initiators or the preferential crack propagation path. As a result, the influence of the 
constituents on the ductile fracture of aluminum alloys has aroused extensive attention [5].

The mechanical properties of heat-treated aluminum alloys are highly dependent on the thermal ageing as the strengthening precipitates are sensitive to both the ageing temperature $\theta$ and the ageing time $t$. Therefore in order to meet industrial requirements in terms of material properties, heat treatments have to be perfectly controlled to precisely manage the ageing process. As a consequence there has been an increasing interest in establishing precise quantitative relationships between the mechanical properties usually expressed in terms of Young modulus $E$ and plastic flow limit $\sigma_{Y}$ as a function of the processing parameters $(\theta, t)$ of the ageing treatment (see for instance [7]). An effective way to characterize these mechanical properties is to perform indentation experiments both as hardness and continuous indentation tests.

The aim of this work is to bridge the gap between ageing, microstructure and material properties for two aluminium alloys and to study, more particularly, the influences of thermal overageing on the mechanical behavior of LFC alloys by using indentation tests. In a first part, the materials and the experimental techniques are presented. The mechanical properties are then analyzed in terms of hardness at the macroscopic and the microscopic level. Properties of the different phases (intermetallics, eutectics) of the microstructure are then investigated. In the second part, the impact of the ageing on the mechanical properties is studied and modeled. In the last part, the microstructure and its evolutions are presented and the results of nanoindentation tests enable to determine the mechanical properties of eutectic and intermetallic phases.

\section{Materials and investigation techniques}

The alloys studied in this paper are two aluminium-silicon alloys commonly used in the automotive industry: an A319 without any heat treatment and an A356 with a T7 heat treatment. The chemical composition of both alloys is presented in Table 1. The T7 heat treatment consists in a thermal homogenization at $540{ }^{\circ} \mathrm{C}$ to dissolve the precipitates, followed by a water quenching and an artificial ageing at $200{ }^{\circ} \mathrm{C}$ during which the $\mathrm{Mg}_{2} \mathrm{Si}$ precipitates are formed [9]. Both LFC alloys - A319 and A356 - were studied in non-aged and various ageing conditions to clarify the influences of over-ageing on the macroscopic mechanical behaviors.

The studied specimens were extracted from industrially produced parts in order to obtain a representative microstructure induced by the lost foam casting process. As shown in Fig. 1, they come from the firedeck intervalve zone of cylinder head prototypes. These specific zones are well known to be highly affected by thermomechanical loading and to be critical for fatigue cracks initiation. A preliminary characterization of the microstructure could be done in terms of Secondary Dendrite Arm Spacing (SDAS) and porosity. The SDAS is around $80 \mu \mathrm{m}$ for LFC alloys, twice as large as the measured SDAS -close to $35 \mu \mathrm{m}$ - in cylinder heads produced by a conventional DC process, which characterize a corser microstructure. Porosities and inclusions are more numerous and highly clustered while iron-, magnesium- and coppercontaining intermetallics are found in the microstructure.

Table 1

Chemical composition of Lost Foam Cast A356 and A319.

\begin{tabular}{lllllllllll}
\hline Material & $\mathrm{Si} \%$ & $\mathrm{Mn} \%$ & $\mathrm{Fe} \%$ & $\mathrm{Mg} \%$ & $\mathrm{Cu} \%$ & $\mathrm{Zn} \%$ & $\mathrm{Ti} \%$ & $\mathrm{Ni} \%$ & $\mathrm{~V} \%$ & $\mathrm{Zr} \%$ \\
\hline A319 & 7.18 & 0.15 & 0.43 & 0.32 & 3.17 & 0.19 & 0.05 & 0.010 & 0.006 & 0.002 \\
A356 (T7) & 6.61 & 0.01 & 0.11 & 0.30 & 0.09 & 0.006 & 0.10 & 0.004 & 0.008 & 0.001 \\
\hline
\end{tabular}

The specimens were submitted to different ageing histories both in terms of maximal temperature $\theta$ and ageing time $t$ until reaching an eventual over-ageing state (steady stabilized). The over-ageing state has been determined by stabilization both in mechanical properties and microstructure composition of the material. For the studied A356 and A319 alloys, this state is observed in the condition of over-ageing equivalent to $500 \mathrm{~h}$ of heating at $250{ }^{\circ} \mathrm{C}$ (the industrial ageing time used at PSA PeugeotCitroën). The tested ageing temperature levels were $150{ }^{\circ} \mathrm{C}, 200{ }^{\circ} \mathrm{C}$ and $250{ }^{\circ} \mathrm{C}$ and the ageing times were $3,6,9,30,60,90,200,300$ and $500 \mathrm{~h}$. Each tested specimen corresponds to a specific ageing condition $(\theta, t)$. For optical and electronic microscopy observations, specimens have been polished with 500, 600, 1200 and 2400 grit papers (coarser polishing). Final polishing was carried out with 6,3 and $1 \mu \mathrm{m}$ diamond pastes (fine polishing). Microstructural observations were conducted on areas of approximately $500 \times 500 \mu \mathrm{m}^{2}$ by using a Scanning Electron Microscope (SEM) S-3600N from Hitachi and a back-scattered electrons (BSE) technique.

Indentation experiments were performed simultaneously at different scales in order to test the global response of the aluminium alloys and to estimate both the aluminum matrix and the different phases mechanical properties separately at the microscopic level. The protocol sums up in:

(i) Vickers hardness experiments with an indentation depth $\delta$ of the order of $50 \mu \mathrm{m}$ and an indentated area $A$ around $100 \mu \mathrm{m}^{2}$, denoted next as macro hardness, are performed using a Test Well Vickers machine, with a $10 \mathrm{~kg}$ weight.

(ii) Berkovitch continuous indentation experiments with an indentation depth $\delta$ of the order of $1 \mu \mathrm{m}$ and an indentated area $A$ around $10 \mu \mathrm{m}^{2}$, denoted next as nanoindentation, are performed with a MTS XP nanoindentor machine using different measuring techniques. A simple hardness test, then a Depth Sensing Indentation (DSI) (see [10,11] for a general presentation) or a continuous stiffness measurement (CSM) (see [1214]) are performed. The latter is characterized by a an oscillating displacement of $2 \mathrm{~nm}$ with a frequency of $45 \mathrm{~Hz}$ imposed to the indenter tip.

Vickers macro hardness tests were performed for different ageing times to estimate the evolution of macroscopic properties of the alloy with respect to the ageing state. 10 measurements were performed on the surface of each specimen and the mean value and standard deviation of macro hardness are presented in Table 2.

Nanoindentation tests were performed to evaluate the mechanical properties at the scale of the heterogeneities of the aluminum matrix and of the intermetallic/eutectic compounds completed with a careful microscopic observations before and after indentation. The nanoindentation technique has been used to measure the hardness $H_{B}$ and to estimate the elastic modulus $E$ of the intermetallic and eutectic phases. A variable maximum load was applied in order to achieve a high spatial resolution while still obtaining reliable indentation data. Tables 3 and 4 summarize the materials, ageing condition and number of indentations on each intermetallic and eutectic phase. The obtained results are discussed in the next sections, following two objectives. First, a macroscopic law is developed to describe the macro hardness evolution versus ageing time. A comprehensive study of the microscopic behavior of each of the component is then proposed with a peculiar attention on the ageing impact.

\subsection{Effects of ageing on macro hardness}

Fig. 2 represents the evolution of macro hardness as a function 

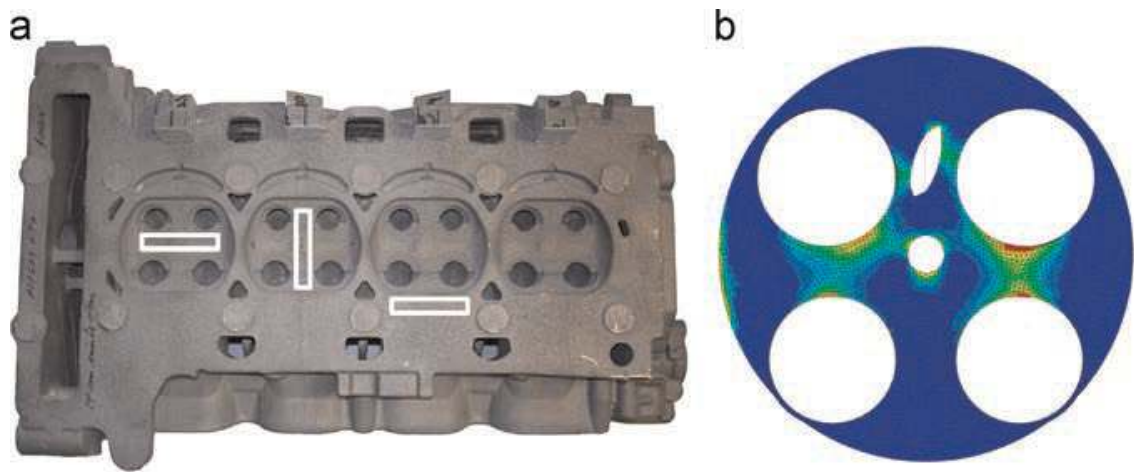

Fig. 1. (a) Location of specimen extraction. (b) Location (in red) of thermal mechanical fatigue critical zones.

of ageing time for the 2 studied alloys. Initial macro hardness measurements for A319-LFC alloy is equal to $103 \mathrm{Hv}$ which is slightly superior (7\%) in comparison with the initial hardness of A356-LFC alloy (96.2 Hv). It was generally observed that when the ageing time increases, the macro hardness decreases until stabilization with a rate that tends to increase with the ageing temperature $[17,19,20]$. Both materials are following this trend. The ageing, however, is faster for the A356 for all the studied temperatures. At $250^{\circ} \mathrm{C}$, the hardness decreases relatively quickly for the two alloys and stabilizes after $300 \mathrm{~h}$ at a value of $40 \mathrm{Hv}$ for the A356 after reaching an already low value $(50 \mathrm{Hv})$ after $30 \mathrm{~h}$ of ageing. Evolution is a little slower for the A319, which only loses $20 \%$ of its hardness after $100 \mathrm{~h}$ at $250{ }^{\circ} \mathrm{C}$. At $200{ }^{\circ} \mathrm{C}$, the same trends are observed with a faster ageing of the $\mathrm{A} 356$. At $150{ }^{\circ} \mathrm{C}$, no significant changes in the macro hardness is observed for both alloys. The results reveal that A319-LFC conserves its macro hardness for a longer ageing time in comparison with A356-LFC. This alloy softens very slowly especially at low temperatures and do not get to steady state condition after $500 \mathrm{~h}$ of ageing.

The measures show significant variability (Fig. 2) for LFC alloys in the first hours of ageing, especially in the case of A319. The fact that any heat treatment was used for this alloy could certainly constitute a good hypothesis to explain variations up to $10 \%$ in the macro hardness values. Many phase transformations are indeed observed in the first hours of ageing. As chemical composition of alloy is often not sufficient to give the required mechanical properties to the material for industrial application, heat treatment methods are usually applied in order to produce softening or hardening effects dependent to the material and the condition [20], essentially by modifying the precipitates in the aluminium matrix [21]. Here, the T7 treatment applied to the A356-LFC alloy induces less variability on the macro hardness values but the material softens more in the few first hours of ageing, leading to an inferior asymptotic value after $500 \mathrm{~h}$ of ageing (Fig. 2).

Fig. 3 enables to compare the mean value of Vickers hardness measurements for A356 and A319 alloy issued with LFC and DC processes as a function of ageing time at $250{ }^{\circ} \mathrm{C}$ and $200{ }^{\circ} \mathrm{C}$ and aims at evaluating both the process and ageing influence on the hardness evolution. In accordance with what is generally observed, the initial macro hardness measurements for LFC process are smaller in comparison with the DC process due to the grain size [5] and to the porosities density [6]. Initial macro hardness for DC process is indeed measured around $110 \mathrm{Hv}$ for both alloys. For the A319 alloy, evolutions observed in Fig. 3b and d highlight comparable hardness evolution rate between the two processes. For the A356 alloy, strong differences arise. In Fig. 3a and c at $200{ }^{\circ} \mathrm{C}$, the evolution of the DC material is much slower while it seems much faster at $250{ }^{\circ} \mathrm{C}$ with an almost immediate ageing. It therefore appears that, from a threshold temperature between $200{ }^{\circ} \mathrm{C}$ and $250{ }^{\circ} \mathrm{C}$, the DC material undergoes accelerated ageing. Being able to anticipate these changes is of primary importance to determine the thermal treatment to be applied to the alloys and a model of hardness evolution versus ageing time has to be developed.

\subsection{Modeling the hardness evolution with ageing}

A review of models to correlate the observed macroscopic hardness to the ageing variables expressed in terms of ageing temperature $\theta$ and time $t$ has been already discussed in the literature by Tiryakioglu et al. [15] or by Zhang et al. [5]. Alloy composition and grain size are often cited to have major influence on the model robustness. Kinetic models of nucleation and growth of precipitates are often used to predict evolutions in hardness for aluminum alloys. It is this assumption that is privileged here. Staley et al. [16] have shown that it is possible to determine the hardness in every moment of a given thermal history from the solute disappearance rate by nucleation and growth of precipitates. This phenomena is observed in aluminium alloys and described by a differential equation as follows:

$$
\frac{d s}{d t}=-A(\theta) .\left(s-s_{\min }(\theta)\right)
$$

$s$ is defined as a concentration of solute inside the solid solution, $A$

Table 2

Evolution of Vickers hardness measurements for LFC alloys(A356 and A319) for various ageing temperature and times.

\begin{tabular}{|c|c|c|c|c|c|c|c|c|c|c|}
\hline A356 $\left({ }^{\circ} \mathrm{C}\right)$ & Ageing time (h) & 3 & 6 & 9 & 25 & 30 & 54 & 102 & 316 & 482 \\
\hline 250 & $H_{V}$ & $74.9 \pm 3.76$ & $68.92 \pm 4.74$ & $65.7 \pm 3.39$ & - & $48.66 \pm 2.12$ & - & - & $40.98 \pm 3.64$ & $43.11 \pm 0.85$ \\
\hline 200 & $H_{V}$ & - & $92.27 \pm 5.28$ & - & $94.05 \pm 4.18$ & - & $85.87 \pm 3.23$ & $81.07 \pm 3.14$ & $61.91 \pm 5.2$ & $60.76 \pm 5.18$ \\
\hline 150 & $H_{V}$ & - & $96.85 \pm 3.34$ & - & $89.98 \pm 3.25$ & - & $104.75 \pm 5.43$ & $100.7 \pm 4.05$ & $93.72 \pm 5.66$ & $93.13 \pm 6.26$ \\
\hline A319 $\left({ }^{\circ} \mathrm{C}\right)$ & Ageing time (h) & 3 & 6 & 9 & 25 & 30 & 54 & 102 & 316 & 482 \\
\hline 250 & $H_{V}$ & $95.61 \pm 5.63$ & $89.51 \pm 1.89$ & $86.56 \pm 4.88$ & $77.77 \pm 9.91$ & $82.01 \pm 3.88$ & $78.36 \pm 7.07$ & $80.81 \pm 3.70$ & $59.87 \pm 4.49$ & $60.81 \pm 2.20$ \\
\hline 200 & $H_{V}$ & $99.47 \pm 5.74$ & $111.28 \pm 7.53$ & $115.63 \pm 7.16$ & $105.33 \pm 11.54$ & $101.01 \pm 4.5$ & $103.83 \pm 14.88$ & $92.55 \pm 6.72$ & $91.97 \pm 3.46$ & $91.75 \pm 4.57$ \\
\hline 150 & $H_{V}$ & $91.12 \pm 9.59$ & $94.93 \pm 4.93$ & $93.83 \pm 6.85$ & $97.37 \pm 2.45$ & $115.6 \pm 6.56$ & $100.95 \pm 7.96$ & $112.93 \pm 3.3$ & $107.43 \pm 16.58$ & $120.82 \pm 2.45$ \\
\hline
\end{tabular}


Table 3

Indentation tests inside different phases for non-aged A319-LFC.

\begin{tabular}{|c|c|c|c|c|c|c|c|c|}
\hline \multirow[t]{2}{*}{ Method } & \multirow[t]{2}{*}{ Material } & \multirow[t]{2}{*}{ Casting process } & \multirow[t]{2}{*}{ Ageing condition } & \multicolumn{2}{|l|}{ Eutectics } & \multicolumn{2}{|c|}{ Intermetallics } & \multirow{2}{*}{$\begin{array}{l}\text { Matrix } \\
\mathrm{Al}\end{array}$} \\
\hline & & & & $\theta-\mathrm{Al}-\mathrm{Al}_{2} \mathrm{Cu}$ & $\mathrm{Al}-\mathrm{Si}$ & $\alpha$-AlFeSi & $\beta$-AlFeSi & \\
\hline Non-CSM & A319 & LFC & Non-aged & 28 & 5 & 3 & 5 & - \\
\hline CSM & A319 & LFC & Non-aged & 3 & - & 4 & 5 & 10 \\
\hline
\end{tabular}

Table 4

Indentation tests inside different phases for non-aged and over-aged A356-LFC.

\begin{tabular}{|c|c|c|c|c|c|c|}
\hline Method & Material & $\begin{array}{l}\text { Casting } \\
\text { process }\end{array}$ & $\begin{array}{l}\text { Ageing } \\
\text { condition }\end{array}$ & $\begin{array}{l}\text { Eutectics } \\
\mathrm{Al}-\mathrm{Si}\end{array}$ & $\begin{array}{l}\text { Intermetallics } \\
\beta \text {-AlFeSi }\end{array}$ & $\begin{array}{l}\text { Matrix } \\
\mathrm{Al}\end{array}$ \\
\hline Non-CSM & A356 & LFC & Non-aged & 4 & 8 & 4 \\
\hline CSM & A356 & LFC & Non-aged & 1 & - & 10 \\
\hline Non-CSM & A356 & LFC & $\begin{array}{l}\text { Aged } \\
(500 \mathrm{~h} \text { at } \\
\left.250^{\circ} \mathrm{C}\right)\end{array}$ & 4 & 12 & 2 \\
\hline
\end{tabular}

$(\theta)$ is a kinetic constant and $s_{\min }(\theta)$ is the equilibrium concentration of solute at temperature $\theta$. Staley et al. [16] also assume that the material conventional yield stress linearly depends on the $s$ parameter in Eq. (1). This hypothesis stays consistent to the hardening mechanism linked to the precipitation process. Assuming a slowly varying temperature, Eq. (1)) can be integrated at a constant temperature which leads directly to the following equation in terms of conventional yield limit $R_{e}$ after an ageing time $t$ at temperature $\theta$ :

$R_{e}(\theta, t)=R_{e, \min }(\theta)+\left(R_{e, \max }(\theta)-R_{e, \min }(\theta)\right) \exp (-k(\theta) t)$

$R_{e, \min }(\theta)$ and $R_{e, \max }(\theta)$ denote the minimum and respectively maximum value of the yield stress for a given ageing temperature:

$R_{e_{\max }}(\theta)=R_{e}(\theta, 0), \quad R_{e_{\min }}(\theta)=R_{e}(\theta, \infty)$

$k$ is a temperature-dependent kinetic parameter. In the present case, this original and simple idea is conserved. Eq. (2), which denotes the influence of temperature on mechanical properties, is therefore integrated in an iterative way to obtain Eq. (3). Inspired from Staley method, it aims at explaining the influences of temperature and macro hardness on mechanical properties of material [18]:

a

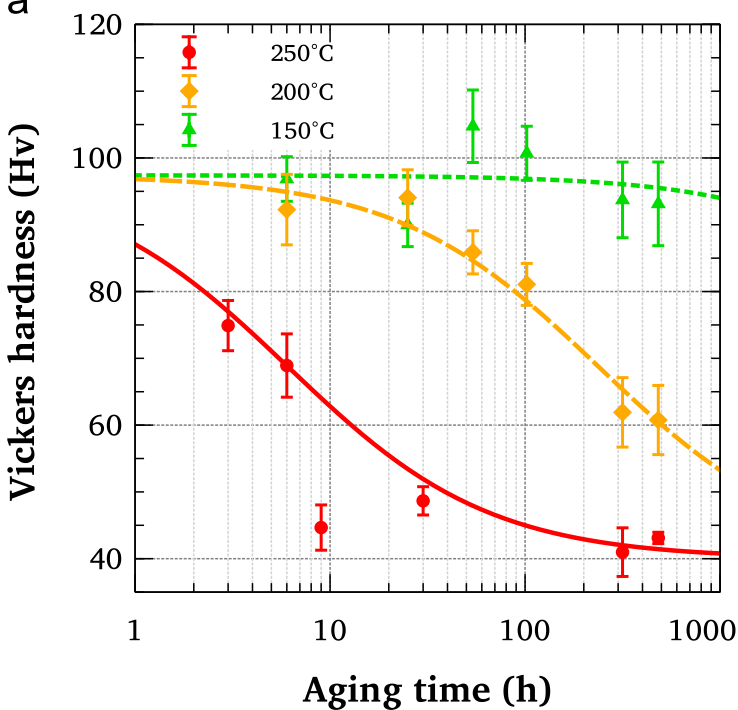

$H_{V}(\theta, \tau)=\frac{\left(H_{V_{\max }}-H_{V_{\min }}\right)-\exp (a \ln \tau+b \ln \theta+c)}{1+\exp (a \ln \tau+b \ln \theta+c)}+H_{V_{\min }}$

where $a, b, c$ are real parameters which are identified from experiments. $H_{V_{\max }}$ and $H_{V_{\min }}$ are respectively the maximal and minimal Vickers hardness. Moreover, as the material microstructure before ageing and after an infinite ageing time is independent of the ageing temperature in the considered temperature range, $H_{V_{\max }}$ and $H_{V_{\min }}$ are assumed to be temperature independent. The values of the parameters of the ageing model: $H_{V_{\max }}, H_{V_{\min }}$ and $a, b, c$ have been identified from experiments by minimizing a least square distance between model and data using a classical fitting procedure. The results are summarized in the following table:

\begin{tabular}{llllll} 
Material & $H_{V_{\max }}(\mathrm{Hv})$ & $H_{V_{\min }}(\mathrm{Hv})$ & $a$ & $b$ & $c$ \\
\hline A319-LFC & 105.0 & 59.9 & 0.68 & 13.46 & -76.45 \\
A356-LFC & 97.4 & 41.0 & 0.84 & 13.81 & -77.76 \\
A319-DC & 109.5 & 72.0 & 0.90 & 18.08 & -102.42 \\
A356-DC & 109.0 & 43.0 & 0.52 & 26.68 & -186.17
\end{tabular}

The comparison between experimental data and the ageing model is presented in Figs. 2 and 3. The model gives a pretty good representation of the Vickers hardness evolution at high ageing temperatures $\left(250{ }^{\circ} \mathrm{C}\right.$ and $\left.200{ }^{\circ} \mathrm{C}\right)$, but seems less appropriate at lower temperatures as $150^{\circ} \mathrm{C}$. As equally observed in [18-20], this could easily be explained by the evolution of the microstructure with time and temperature during the ageing process, which is highly correlated with the hardness. Microstructural evolution essentially takes place at temperatures higher than $200{ }^{\circ} \mathrm{C}$ even if some changes begin to appear around $150^{\circ} \mathrm{C}$. The successive phase transformations produce larger and larger precipitates, so that the

b

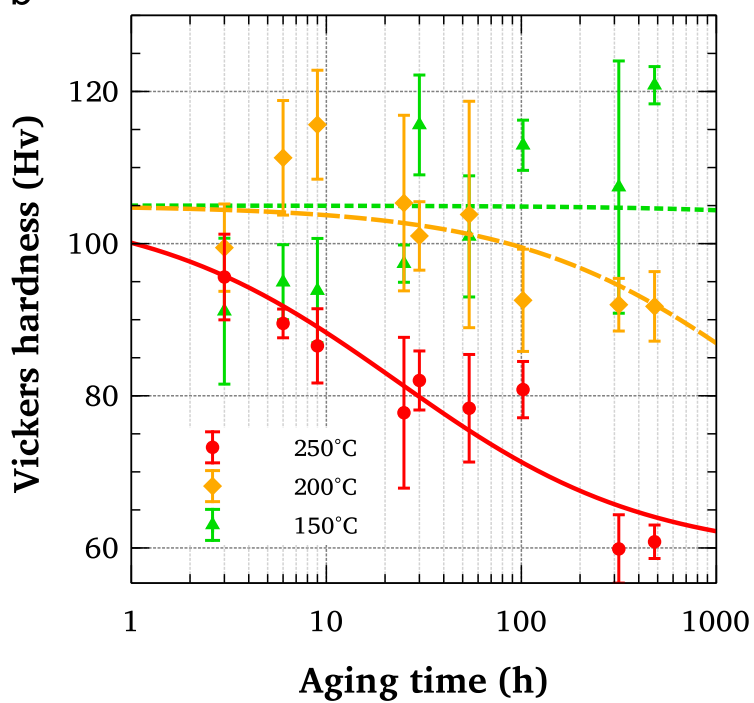

Fig. 2. Comparison of macro hardness as a function of aging time between 250,200 and $150{ }^{\circ} \mathrm{C}$ for (a) A319-LFC alloy and (b) A356-LFC alloy. 

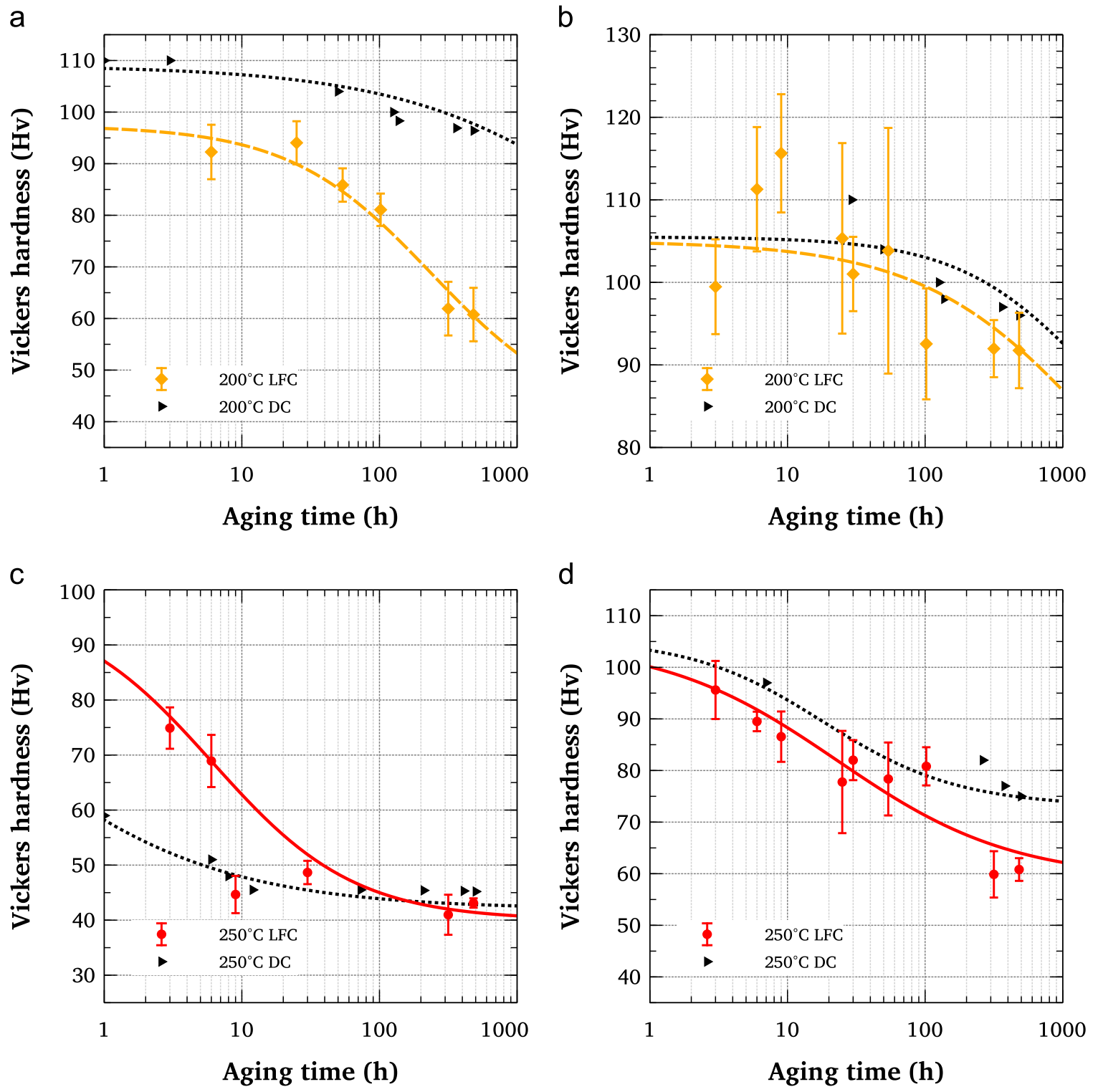

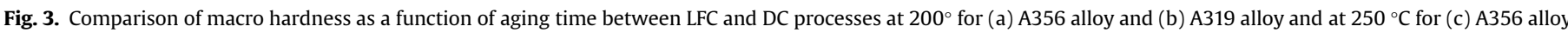
and (d) A319 alloy.

matrix hardening becomes lower and lower. At $150^{\circ} \mathrm{C}$, the phase transformations kinetic is so slow as the energy brought by temperature is very low that the large precipitations happens after long hours of artificial ageing. That is the reason why the proposed hardness model does not well match the results at $150{ }^{\circ} \mathrm{C}$ for the two studied alloy. It is clear that at this temperature, measurements exhibit a very slow evolution of the hardness and a strong difficulty to analyze the results due to the data variability.

In order to understand the link between the observed evolutions of macroscopic hardness during the ageing process and the part played by each of the microstructure compounds in its evolution, it seems therefore interesting to perform microstructural observations coupled with nanoindentation tests.

\section{Microstructural evolutions with ageing}

A series of microstructural observations for both the A319-LFC and the A356-LFC alloy were performed in order to track its evolution with ageing and giving first hypothesis to explain hardness evolutions. The study focused on the microstructural states before and after the artificial over-ageing for the intermetallics phase and the eutectic structure. Silicon with magnesium, iron or copper indeed causes the formation of specific intermetallics or eutectic phases inside the microstructure of the alloys.

Fig. 4 represents typical observations, for different scale, of the microstructures of the studied alloys. A356-LFC shows far less intermetallic phases than A319-LFC. SEM images were therefore analyzed by means of ImageJ software (version 1.44) in order to estimate the ratio of intermetallics and porosities for each material and a statistical analyze was performed in order to determine the mean equivalent diameter of these phases in each alloy (Table 5).

The total surface which was analyzed in the case of non-aged A319-LFC was around $51.2 \mathrm{~mm}^{2}$ and $63.6 \mathrm{~mm}^{2}$ for non-aged A356LFC. Image analysis revealed that phases in initial microstructure of both alloys have approximately the same size as seen in Fig. 4 and Table 5. Analyzing the microstructure, different phases appear:

- Iron-containing intermetallics: Iron-containing intermetallics phases are the most observed among intermetallic components, which is a crucial point as they are known to be sometimes 
a

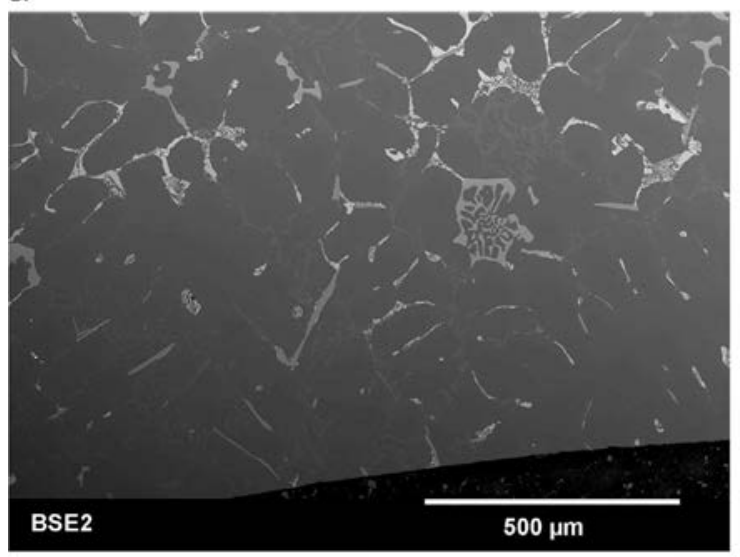

C

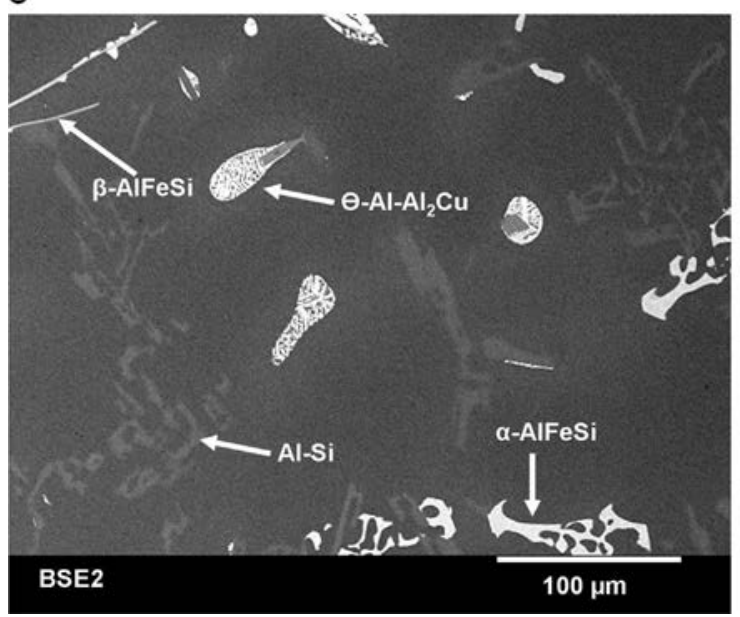

b

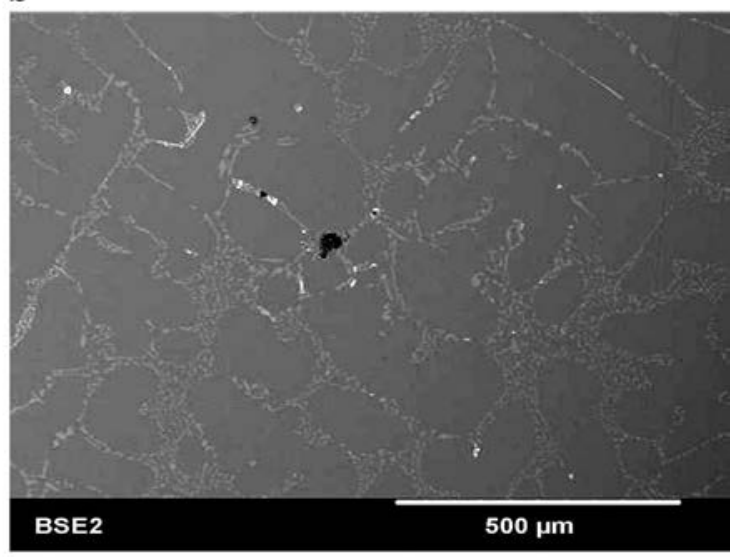

d

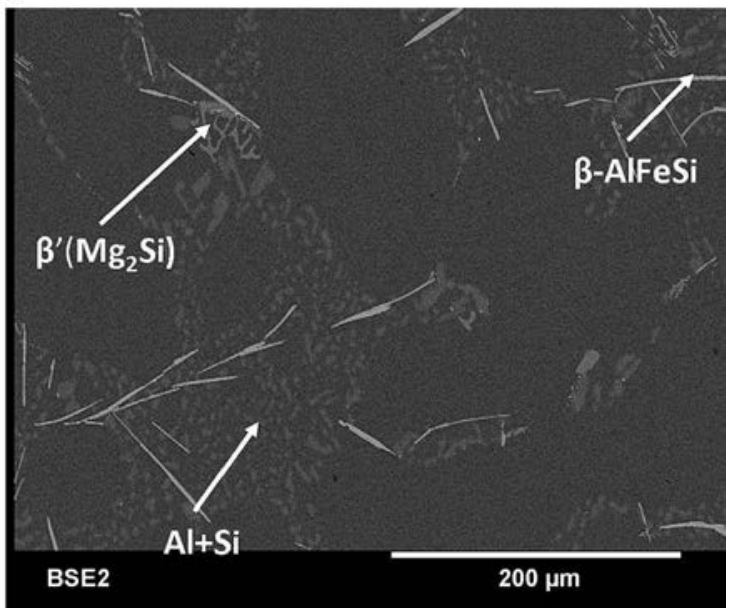

Fig. 4. Initial microstructure: (a) and (c) A319-LFC alloy, LFC; (b) and (d) A356-LFC alloy.

Table 5

Mean equivalent diameter of for intermetallic phases and porosity in $\mu \mathrm{m}$ for the non-aged A356 and A319 aluminum alloys.

\begin{tabular}{lllllll}
\hline Alloy & $\begin{array}{l}\text { Al-Si } \\
\text { eutectic }\end{array}$ & $\beta$-AlFeSi & $\alpha$-AlFeSi & $\theta-\mathrm{Al}-\mathrm{Al}_{2} \mathrm{Cu}$ & Porosity & DAS \\
\hline $\begin{array}{c}\text { A319-LFC } \\
\text { A356-LFC }\end{array}$ & 7.4 & 8 & 14 & 9.9 & 16 & 73.7 \\
(T7) & 6.5 & 7.8 & - & - & 20 & 80 \\
\hline
\end{tabular}

deleterious to mechanical properties $[22,23]$. Two pre-eutectic iron-containing intermetallics are observed in the studied alloy: $\alpha$-AlFeSi $\left(\mathrm{Al}_{15} \mathrm{Fe}_{3} \mathrm{Mn}_{3} \mathrm{Si}_{2}\right.$ ) and the $\beta$-AlFeSi ( $\mathrm{Al}_{5} \mathrm{FeSi}$ ). $\alpha$-AlFeSi phases can generally be found with different compositions and morphologies depending on the quantity of 'iron-correcting' elements, such as Magnesium and Manganese, but most of the time, their morphology takes the form of complex aggregates that are called 'Chinese scripts' or script phases [24]. These $\alpha$ AlFeSi intermetallic phases, which have a destructive effect on the material ductility [22], are only found in the A319-LFC alloy as seen in Fig. $4 \mathrm{a}$ and c. Their mean equivalent diameter is equal to $14 \mu \mathrm{m}$, making it one of the larger elements of the microstructure, and one of the significant differences between the two alloys.

Iron correcting elements reduce the amount of $\alpha$-AlFeSi phases and form a less harmful $\beta$-AlFeSi phases which are the critical iron-containing intermetallic compounds to focus on when analyzing A356-LFC alloy. This phase is found in both alloy along grain boundaries and also has a detrimental needle-like morphology [25-28,24,29]. It has been observed that as the cooling rate decreases in LFC compared with DC process, $\beta$ AlFeSi phase increases in length and thereby decreases the basic mechanical properties such as yield and ultimate stress [30]. Their mean equivalent diameter is measured equal to $8 \mu \mathrm{m}$ in both alloys, categorizing them as small to mid-sized elements, especially in the A319-LFC.

- Al-Si eutectics: Al-Si eutectics improve the castability and the flowability of the aluminum matrix. They are another significant precipitations appearing as thin plate-like structures (acicular). The morphology of the silicon is quite dependent on the cooling rate and on the amount of Strontium in the alloy chemical composition. With low cooling rates in the case of LFC and the given Strontium concentration, silicon appears coarser as seen in Fig. $4 \mathrm{c}$ and $\mathrm{d}$ [22]. Their mean equivalent diameter is similar to the one of $\beta$-AlFeSi.

- Copper-containing intermetallics (A319 alloy): The presence of copper in chemical composition of A319-LFC causes the formation of $\theta-\mathrm{Al}-\mathrm{Al}_{2} \mathrm{Cu}$ intermetallic phase. Copper-based eutectics in aluminum alloys crystallize at the end of solidification in the remaining inter-dendritic liquid. $\theta-\mathrm{Al}-\mathrm{Al}_{2} \mathrm{Cu}$ phase appears in A319-LFC as eutectic pockets intermixed with the aluminum matrix as seen in Fig. 4c, confirming the observations by [31,32].

- Magnesium-containing intermetallics (A356 alloy): $\beta^{\prime}-\mathrm{Mg}_{2} \mathrm{Si}$ phase has small black script morphology and develops in the final stages of solidification of A356 at very high cooling rates 
a

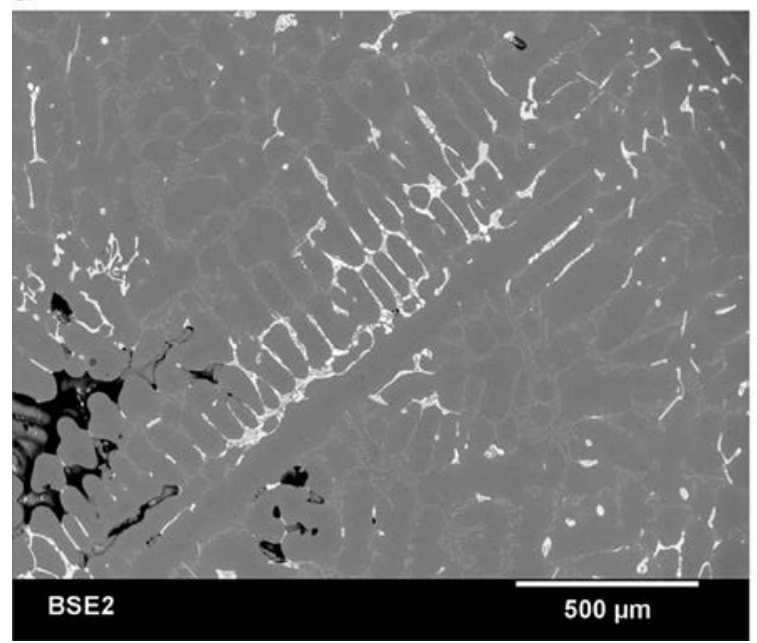

b

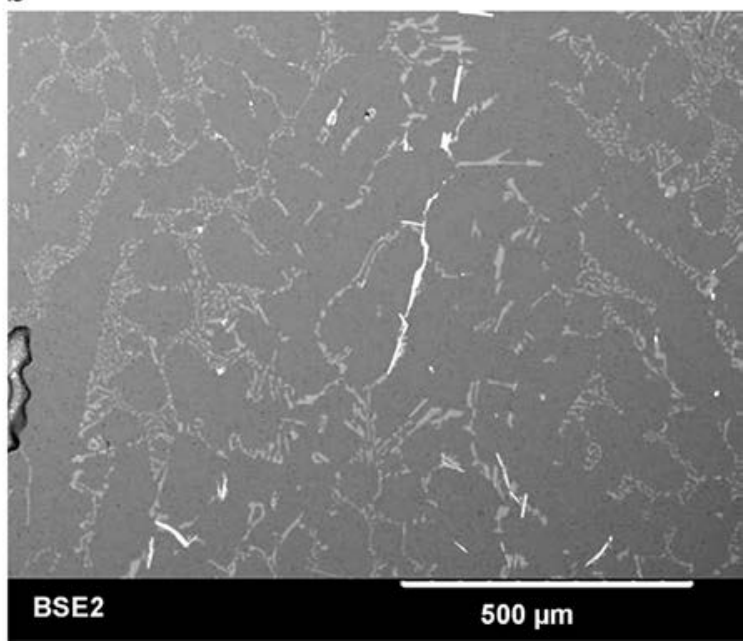

Fig. 5. (a) Microstructure of over-aged A319-LFC alloy; (b) microstructure of over-aged A356-LFC alloy.

$[26,33,34]$. Due to the low cooling rate of LFC, a very small amount of $\theta^{\prime}-\mathrm{Mg}_{2} \mathrm{Si}$ phases were observed in the final microstructure of the A356-LFC. Therefore, this compound will not be studied in the following.

- Porosities: It seems that both materials approximately have the same ratio of porosity $(0.5-0.6 \%)$ and that their mean diameter is between 0.1 and $0.2 \mathrm{~mm}$. The ratio of porosity in the matrix is quite important for LFC, compared with DC materials which is around $0.01 \%$ for $70 \mathrm{~mm}^{2}$ of analyzed surface.

Same phases were observed in the microstructure of both LFC materials in over-aged condition. It seems that in this condition of over-aging, the $\beta$-AlFeSi phases in A356-LFC and the $\theta-\mathrm{Al}-\mathrm{Al}_{2} \mathrm{Cu}$ phases in A319-LFC are mostly gathered around the boundary cells

b
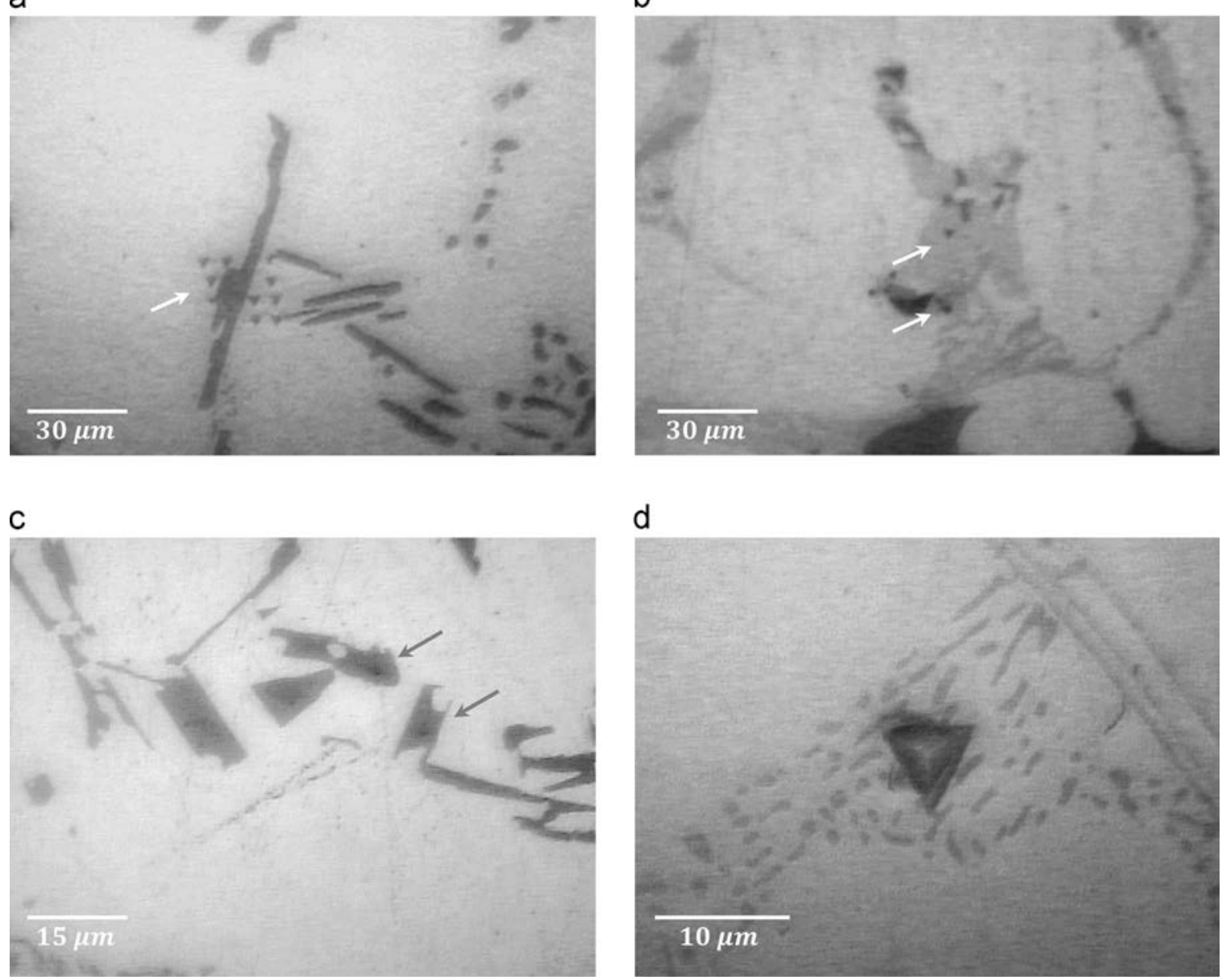

d

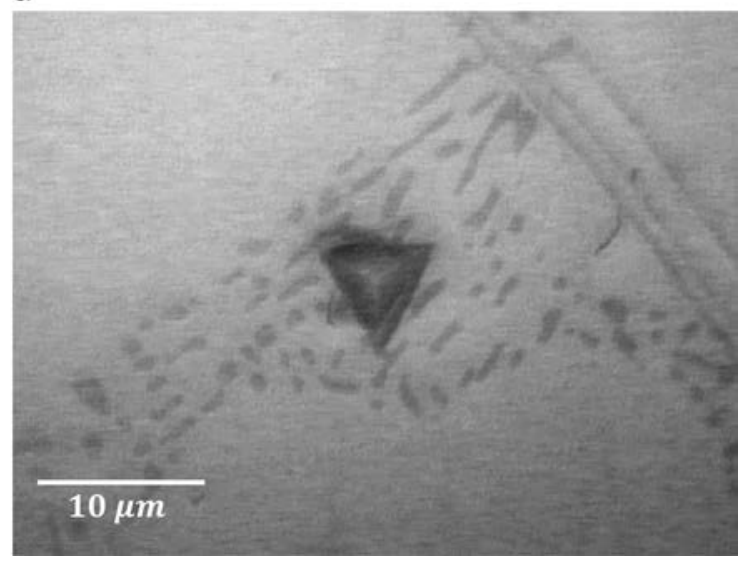

Fig. 6. Indentation tests in A319-LFC alloy for (a) $\beta$-AlFeSi intermetallic phase and $\mathrm{Al}$ matrix; (b) $\theta-\mathrm{Al}-\mathrm{Al}_{2} \mathrm{Cu}$ eutectic phase; (c) $\alpha$-AlFeSi intermetallic phase and (d) $\mathrm{AlSi}$ eutectic phase. 
(Fig. 5). It is the only significant changing of microstructure in mesoscopic scales ( $\approx 500 \mu \mathrm{m}-1 \mathrm{~mm}$ ) which was observed by over-aging the materials. It seems than that phases transformation and microstructure evolution as a function of ageing are not observable at mesocopic scale and require some TEM (Transmission Electron Microscopy) observations during ageing [20]. However, intermetallic compounds play a part in the alloy mechanical properties.

The higher level of initial macro hardness for A319 can for instance be explained precisely by the microstructure of this material. The inferior DAS value (DAS $=73.7 \mu \mathrm{m}$ ) is the main reason for high initial macro hardness of LFC materials. A319 LFC aged quite slowly in comparing with $\mathrm{A} 356$ due to $\alpha$-AlFeSi and $\theta-\mathrm{Al}-\mathrm{Al}_{2} \mathrm{Cu}$ phases which conserve their hardening effects especially at high temperatures as shown by [20].

In the next section the influences of over-ageing on each phase are studied by means of nanoindentation tests.
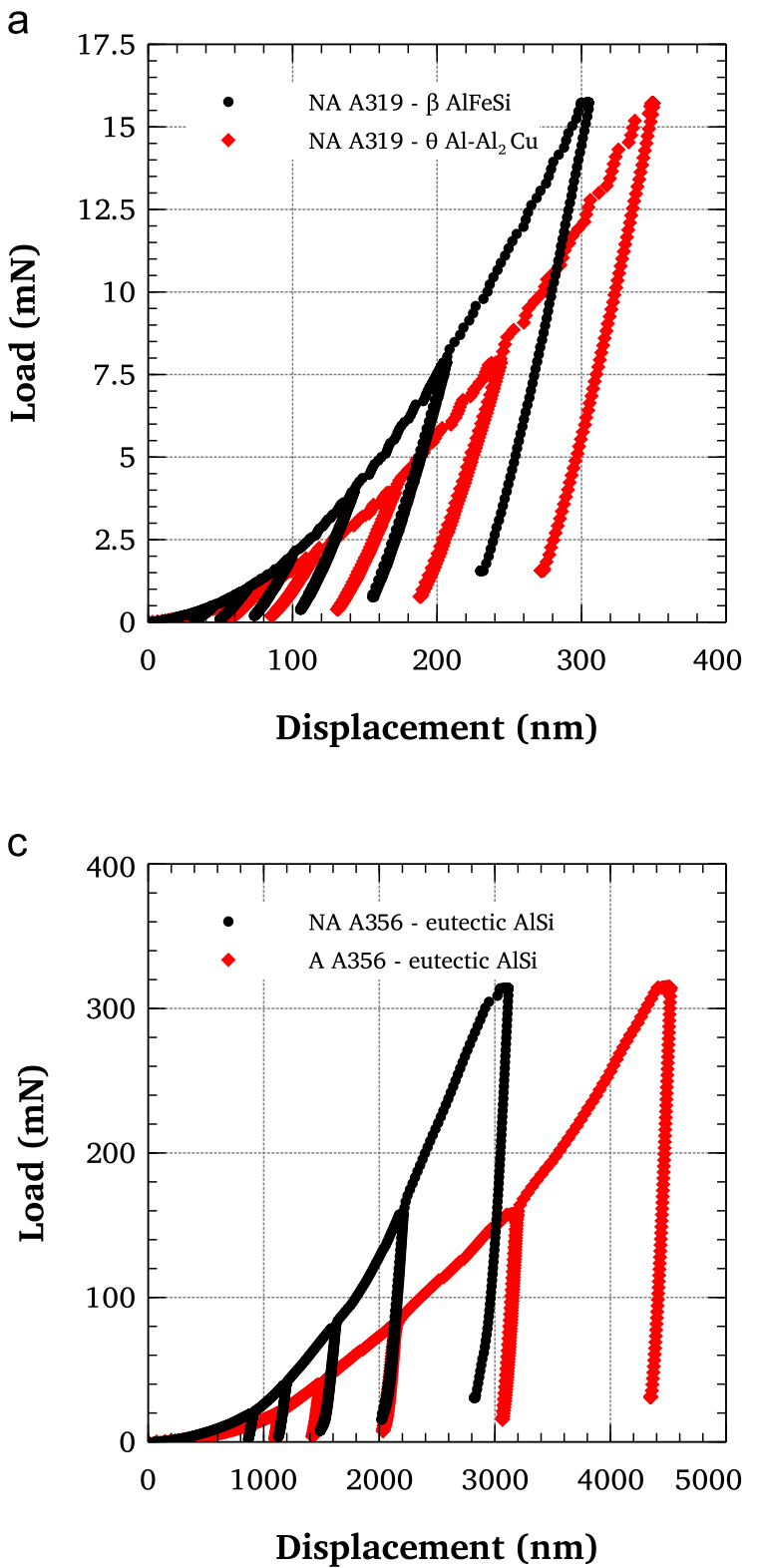

\section{Nanoindentation investigations}

The nanoindentation technique has been used to measure hardness and to determine elastic modulus of the following microstructural components: Al-Si eutectics, $\beta$-AlFeSi intermetallics, $\alpha$-AlFeSi and $\theta-\mathrm{Al}-\mathrm{Al}_{2} \mathrm{Cu}$ intermetallic phases for A319-LFC (see Fig. 6). These tests aimed at evaluating the influence of ageing on these mechanical properties.

Fig. 7 represents the typical load/displacement curves obtained by the performed nanoindentation tests. Successive indentations are made for increasing applied stress levels using a Berkovitch type indenter. Load and displacement are jointly monitored to provide mechanical behavior estimation. Small sudden displacement discontinuity pop-in events were observed during the loading as mentioned by [35]. These small pop-ins (Fig. 7a and d for instance) are more pronounced for the brittle intermetallic phases. As reported in the literature, it seems that during loading, cracks can initiate in brittle phases, which cause small pop-ins and discontinuities in the load-displacement curve [36].

b

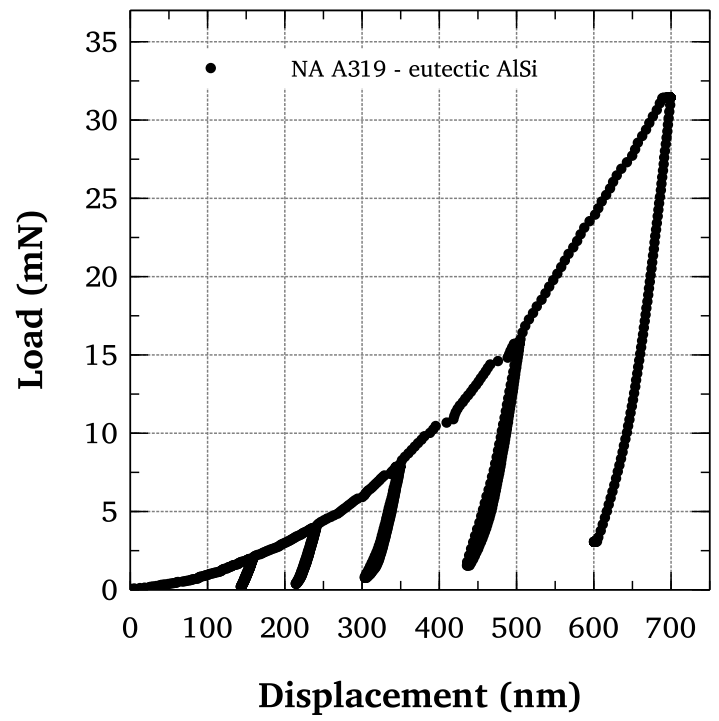

d

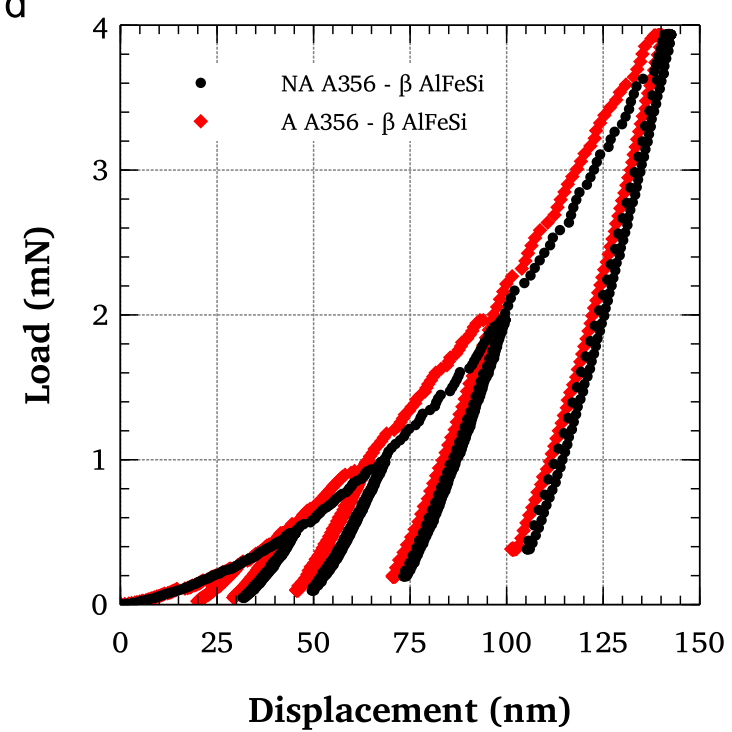

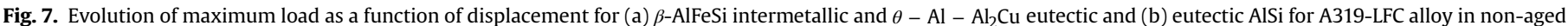
condition, and for (c) eutectic AlSi and (d) $\beta$-AlFeSi intermetallic for A356-LFC alloy in non-aged and overaged conditions. 
As seen in Fig. 6a, the indenter size is more important than the size of needle-like $\beta$-AlFeSi intermetallic phases (around $10 \mu \mathrm{m}$ ); indentation of the aluminum matrix interface might therefore happen. In order to reduce the influence of such interference on the mechanical analysis, several measurements were performed and finally only the indentation tests with $100 \%$ of covering with the intermetallic phase are retained.

In Fig. 7a, indentation test for $\beta$-AlFeSi and $\theta-\mathrm{Al}_{2} \mathrm{Cu}$ phases for A319-LFC alloy in non-aged condition is represented. Indentations are made of 5 peak loads of 1, 2, 4, 8 and $16 \mathrm{mN}$ at room temperature. Displacements appear to be more important in $\theta-\mathrm{Al}-\mathrm{Al}_{2} \mathrm{Cu}$ eutectic phase for all loadings in comparison with $\beta$-AlFeSi intermetallic phase. $\theta-\mathrm{Al}-\mathrm{Al}_{2} \mathrm{Cu}$ eutectic phase has therefore a lower hardness than $\beta$-AlFeSi intermetallic phase.

The influences of ageing is illustrated by comparing both $\mathrm{Al}-\mathrm{Si}$ eutectics and $\beta$-AlFeSi intermetallic phases for A356 material in aged and non-aged conditions (Fig. $7 \mathrm{c}$ and $\mathrm{d}$ ). Indentations are made to 5 peak loads of $0.25,0.5,1,2$ and $4 \mathrm{mN}$ for $\beta$-AlFeSi intermetallic phases and 25,50, 75, 150 and $300 \mathrm{mN}$ for AlSi eutectics. Artificially aged Al-Si eutectic phases have a lower hardness and thus elastic modulus in comparison with non-aged

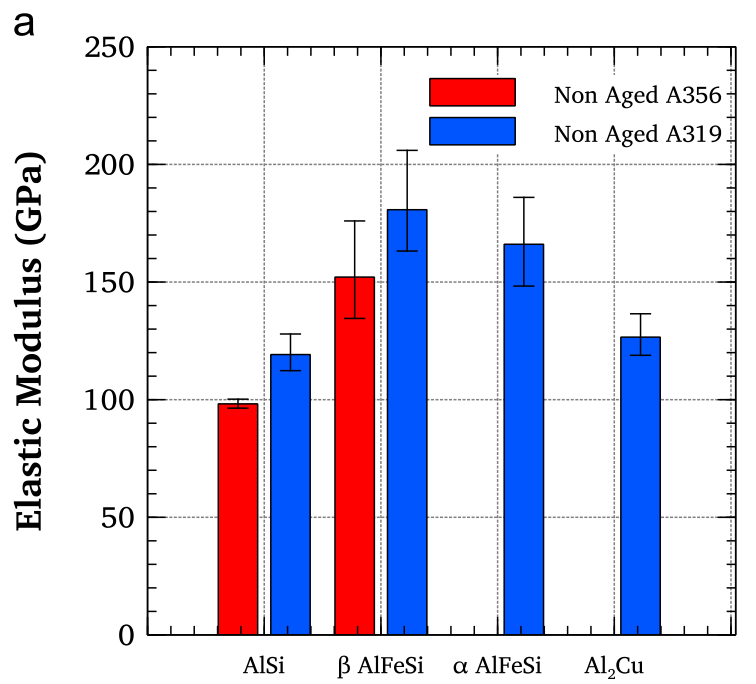

Components

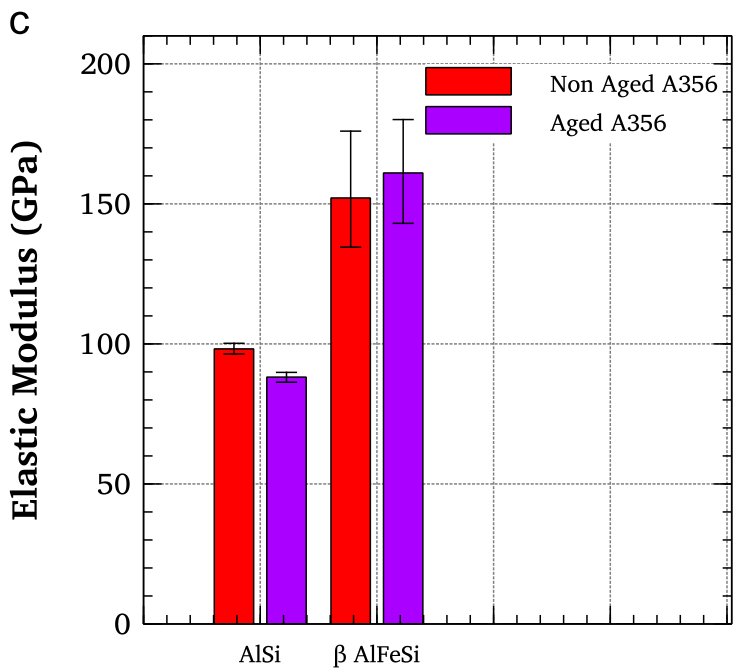

Components phases. On the contrary, ageing does not have any influence on the hardness of $\beta$-AlFeSi intermetallic phases. Moreover, comparison of Fig. 7c and d shows that the curves reflect a high degree of elastic recovery during unloading of $\beta$-AlFeSi intermetallic phases, comparing with AlSi eutectics. This confirms that $\beta$-AlFeSi intermetallics present a higher Young modulus for both aged and nonaged phases [36]. This also confirms that the hard phases are not or little affected by the ageing process. Therefore, the more the alloy contains of these intermetallic compounds, the longer and the more moderate the ageing process will be, as is the case for the A319-LFC alloy.

The slope of the load displacement curve, upon unloading, is indicative of the stiffness of the contact between the indenter and the tested material. This value generally includes a contribution from both the material being tested and the response of the test device itself. The stiffness of the contact can be used to obtain the tested phase Young's modulus and micro hardness [10]. In order to analyze the influence of the over-ageing process, mean value of micro hardness and elastic modulus for different maximum loads were compared for the two LFC alloys. Mean values and standard

b

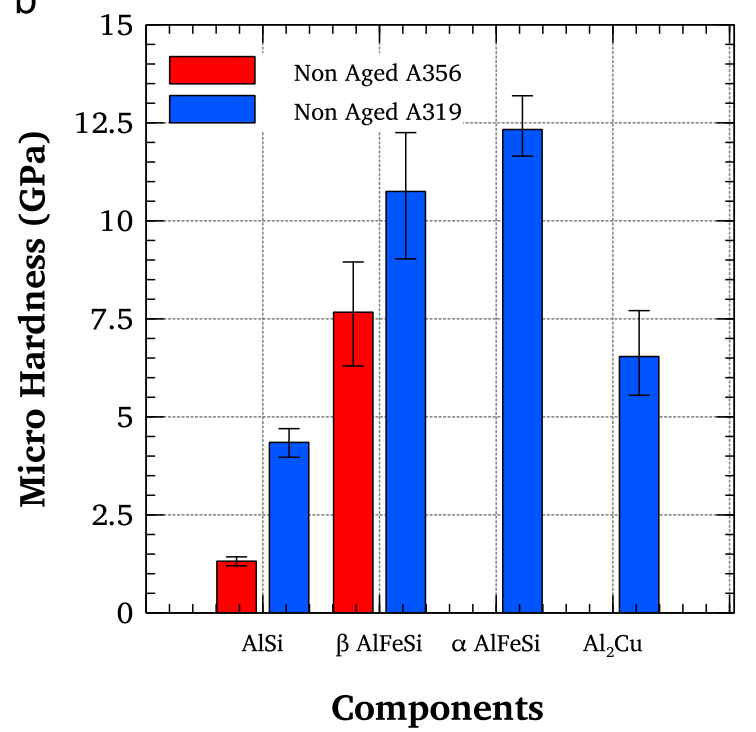

d

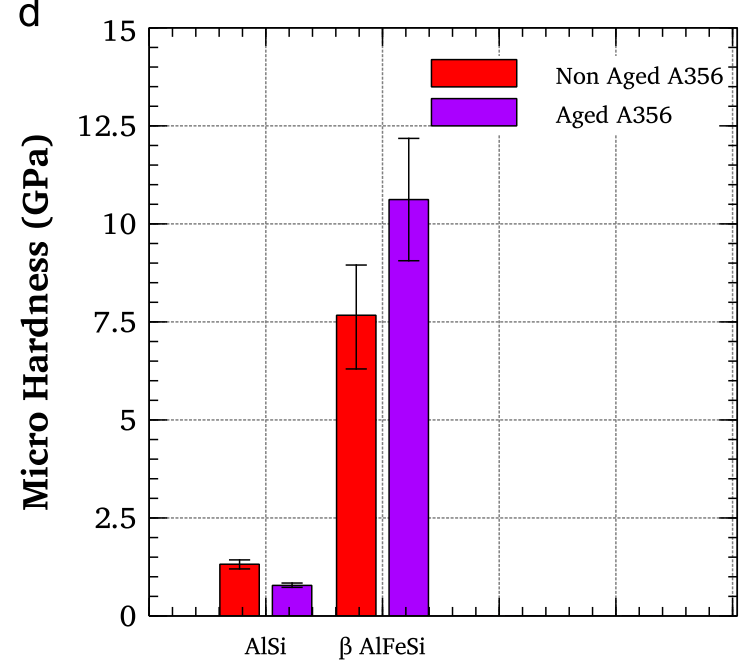

\section{Components}

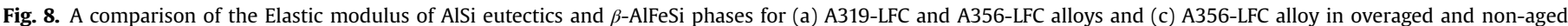

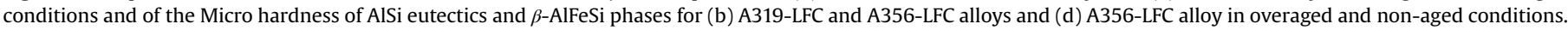


Table 6

Chemical composition of Al-Si alloy compared to our LFC alloy.

\begin{tabular}{lccccccc}
\hline Material & $\mathrm{Si} \%$ & $\mathrm{Cu} \%$ & $\mathrm{Ni} \%$ & $\mathrm{Mg} \%$ & $\mathrm{Fe} \%$ & $\mathrm{Mn} \%$ & $\mathrm{Al} \%$ \\
\hline Al-Si alloy & 14.81 & 2.06 & 1.58 & 0.92 & 0.33 & 0.02 & Bal. \\
\hline
\end{tabular}

Table 7

Comparison of experimental results with the literature data wherever available.

\begin{tabular}{|c|c|c|c|c|c|c|}
\hline \multirow[t]{2}{*}{ Phase } & \multicolumn{2}{|c|}{ Experimental data } & \multirow{2}{*}{$\begin{array}{l}\text { Load }_{\text {max }} \\
(\mathrm{mN})\end{array}$} & \multicolumn{2}{|c|}{ Literature data } & \multirow{2}{*}{$\begin{array}{l}\text { Load }_{\text {max }} \\
(\mathrm{mN})\end{array}$} \\
\hline & $E(\mathrm{GPa})$ & $H(\mathrm{GPa})$ & & $E(\mathrm{GPa})$ & $H(\mathrm{GPa})$ & \\
\hline AlSi eutectic & 119.177 & 4.35 & 300 & - & & \\
\hline $\begin{array}{l}\alpha \text {-AlFeSi } \\
\text { phase }\end{array}$ & 166.06 & 12.33 & 16 & $\begin{array}{l}175.32 \\
{[39]}\end{array}$ & $10.81[39]$ & 20 \\
\hline$\beta$-AlFeSi phase & 180.75 & 10.74 & 16 & - & & - \\
\hline $\begin{array}{c}\theta-\mathrm{Al}-\mathrm{Al}_{2} \mathrm{Cu} \\
\text { eutectic }\end{array}$ & 126.58 & 6.54 & 16 & $\begin{array}{l}104.1 \\
{[40,41]}\end{array}$ & $4-6[42]$ & 20 \\
\hline
\end{tabular}

deviation from the different load levels are investigated.

Fig. 8a and b compares the elastic modulus and hardness measurements for Al-Si eutectics and $\beta$-AlFeSi for both alloy and $\alpha$-AlFeSi intermetallic phase and $\theta-\mathrm{Al}-\mathrm{Al}_{2} \mathrm{Cu}$ eutectic phase for A319-LFC. Unsurprisingly, the elastic modulus of each of the components is greater than the Young modulus of the aluminum matrix (about $70 \mathrm{GPa}$ ). The Al-Si eutectics and the $\beta$-AlFeSi intermetallic are globally harder and have a higher modulus in the A319-LFC alloy, certainly because of the light differences in the chemical compositions. Although the dispersion is important for the intermetallic compound, there is a gap of about $15 \%$ in favor of the A319. Furthermore, in the A319, $\alpha$-AlFeSi intermetallics also have both a high modulus and hardness while the $\theta-\mathrm{Al}-\mathrm{Al}_{2} \mathrm{Cu}$ eutectic properties are equivalent to the Al-Si eutectic ones.

Fig. $8 \mathrm{c}$ and $\mathrm{d}$ compares the elastic modulus and hardness measurements for Al-Si eutectics and $\beta$-AlFeSi for A356 LFC alloy in non-aged and over-aged conditions. The results of the nanoindentation tests reveal that the $\beta$-AlFeSi phases possess higher hardness and elastic modulus in comparison with Al-Si eutectics, whatever the condition of ageing. Both elastic modulus and micro hardness of AlSi eutectics decreased after over-ageing. On the contrary, elastic modulus of $\beta$-AlFeSi phases stays almost identical while the micro hardness increases strongly after over-ageing.

These comparisons enable to explain the observations made in the previous sections. The A319-LFC will naturally have a higher initial hardness compared to the A356-LFC due to the presence of a greater number of hard intermetallic compounds. The latter exhibit little or no change in hardness with the artificial ageing, unlike the eutectic Al-Si and the aluminum matrix [21]. In fact, the maintenance of a higher macrohardness with aging for the A319 is thereby also justified.

Finally, Table 7 offers a comparison between the obtained elastic modulus and micro hardness values with values coming from the literature, for an aluminum alloys possessing a close chemical composition (see [39], composition given in Table 6). The addition of copper and nickel at about $2 \%$ each in mass in order to improve the fatigue strength, leads to higher hardness and strength at elevated temperature. At room temperature, small differences occur for elastic modulus and hardness values for $\alpha$ AlFeSi and $\theta-\mathrm{Al}-\mathrm{Al}_{2} \mathrm{Cu}$ phases thus highlighting good consistency of our results.

\section{Conclusion}

Vickers macro hardness tests were performed to study the macroscopic mechanical behaviors of two LFC (Lost Foam Casting) aluminum alloys, to compare them with more traditional DC (Die Casting) aluminium alloys and to measure the influence of artificial ageing. It was shown that whatever the casting process, A319 slowly softens in comparison with A356 and shows higher value of hardness before and after over-ageing. The LFC process also exhibits lower initial hardness in comparison with DC process.

The evolution of hardness versus ageing time was described by the difference in terms of the microstructure. Different components (eutectics, intermetallics) in both LFC alloys were compared and it was observed that the iron-based and copper-based intermetallics potentially affect the elastic properties and the ductility of the materials by their morphology or mechanical properties.

Nanoindentation tests were therefore performed to evaluate the mechanical stiffness of each component and also to observe their evolution during material ageing. The results show that ironbased intermetallics exhibit a high elastic modulus $(E=166-$ $180 \mathrm{GPa})$ in comparison with the other eutectic/intermetallic phases. This modulus is moreover not affected by the artificial ageing. These components should thus play a crucial part in the alloy initial hardness and its decrease rate and stabilization during ageing.

\section{Acknowledgments}

The authors thanks Alain Iost from ENSAM Lille (LML Laboratory) for the nanoindentation tests. This work was supported by PSA Peugeot-Citroen and has received the financial support of the French Minister of Science (CIFRE 287/2008), which are both gratefully acknowledged.

\section{References}

[1] R.W. Neu, H. Sehitoglu, Thermomechanical fatigue, oxydation and creep. Part I. Damage mechanisms. Part II. Life predictions, Metall. Trans. A 20A (1989) $1755-1783$.

[2] M. Gupta, EJ. Lavernia, Effect of processing on the microstructural variation and heat-treatment response of a hypereutectic Al-Si alloy, J. Mater. Process. Technol. 54 (1995) 261

[3] J. Campbell, The concept of net shape for castings, Mater. Des. 21 (2000) 373.

[4] C.H. Caceres, Microstructure design and heat treatment selection for casting alloys using the quality index, J. Mater. Eng. Perform. 9 (2000) 215-221.

[5] G.J. Zhang, R.H. Wang, S.P. Yuan, G. Liu, S. Scudino, J. Sun, K.H. Chen, Influence of constituents on the ductile fracture of $\mathrm{Al}-\mathrm{Cu}-\mathrm{Mg}$ alloys: modulated by the ging treatment, Mater. Sci. Eng. 526 (2009) 171-176.

[6] B. Kang, Y. Kim, G. Cho, K. Choe, K. Lee, Density and mechanical properties of aluminum lost foam casting by pressurization during solidification, J. Mater. Sci. Technol. 23 (6) (2007).

[7] S.P. Yuan, G. Liu, R.H. Wang, G.-J. Zhang, X. Pu, J. Sun, K.H. Chen, Aging-dependent coupling effect of multiple precipitates on the ductile fracture of heat-treatable aluminum alloys, Mater. Sci. 499 (2009) 387-395.

[9] R. Develay, Heat Treatment of Aluminum Alloys, Technical Report, Technique d'ingénieur-traite matériaux métallique.

[10] W.C. Oliver, G.M. Pharr, Measurement of hardness and elastic modulus by instrumented indentation: advances in understanding and refinements to methodology, J. Mater. Res. 19 (2004) 3-20.

[11] Y. Golovin, Nanoindentation and mechanical properties of solids in submicrovolumes, thin near-surface layers, and films, Phys. Solid State 50 (2008) $22-36$.

[12] W.C. Oliver, G.M. Pharr, An improved technique for determining hardness and elastic modulus using load and displacement sensing indentation experiments, J. Mater. Res. 7 (1992) 64-83.

[13] B.N. Lucas, W.C. Oliver, J.E. Swindeman, The dynamics of frequency-specific, depth-sensing indentation testing, fundamentals of nanoindentation and nanotribology, Mater. Res. Symp. Proc. 522 (1998) 3-14.

[14] J.B. Pethica, W.C. Oliver, Tip surface interactions in STM and AFM, Phys. Scr. T 19 (1987) 61

[15] M. Tiryakioglu, J. Campbell, J.T. Staley, On macrohardness testing of Al-7 wt \% $\mathrm{Si}-\mathrm{Mg}$ alloys. II. An evaluation of models for hardness and yield strength relationships, Materiala A 361 (2003) 240-248.

[16] J.T. Staley, R.D. Doherty, A.P. Jaworski, Improved model to predict properties of aluminium alloy products after continuous cooling, Metall. Trans. A 24 (11) (1993) 2417-2427. 
[17] J.J. Thomas, L. Verger, A. Bignonnet, E. Charkaluk, Thermomechanical design in the automotive industry, Fatigue Fract. Eng. Mater. Struct. 27 (10) (2004) 887-895.

[18] L. Verger, Sur la fatigue thérmomecanique d'un alliage d'aluminium (French Ph.D. thesis), Ecole Polytechnique, 2002.

[19] E. Nicouleau-Bourles, Etude expérimental et numérique du vieillissement d'un alliage d'aluminium: application aux culasses automobiles (French Ph.D. thesis), Ecole Nationale Supérieure des Mines de Paris, 1999.

[20] B. Barlas, Etude du comportement et de l'endommagement en fatigue d'alliages d'aluminium de fonderie (French Ph.D. thesis), Ecole Nationale Supérieure des Mines de Paris, 2004.

[21] P. Osmond, Etude du vieillissement á chaud des alliages d'aluminium pour culasses diesel et prise en compte dans le dimensionnement (French Ph.D. thesis), Ecole Nationale Supérieure des Mines de Paris, 2011.

[22] R. Albonetti, Porosity and Intermetallic Formation in Lost Foam Casting of A356 Alloy (Master's thesis), The University of Western Ontario, 2000.

[23] G. Ran, J.E. Zhou, Q.G. Wang, Precipitates and tensile fracture mechanism in a sand cast A356 aluminum alloy, J. Mater. Process. Technol. 207 (2008) 46-52.

[24] L. Ananthanarayanan, F.H. Samuel, J.E. Gnizleski, Crystallization behavior of bon- containing intermetallic compounds in 319 aluminium alloys, Metall. Trans. A 25A (1994) 1761-1773.

[25] O.V. Orren, J.E. Evensen, T.B. Pedercen, Microstructure and mechanical properties of AlSi(Mg) casting alloys, AFS Trans. 92 (1984) 459-466.

[26] B. Closset, J.E. Gnzleski, Structure and properties of hypoeutectic Al-Si-Mg alloys modified with pure strontium, Metall. Trans. A 13A (1982) 945-951.

[27] S. Murali, K.S. Raman, K.S.S. Murthy, Effect of magnesium, iron (impurity) and cooling rates on the fracture toughness of AlSi7Mg0.3 casting alloy, Mater. Sci. Eng. A 151 (1992) 1-10.

[28] P.N. Crepeau, Effect of iron in Al-Si casting alloys, AFS Trans. 103 (1995) 361-366.
[29] G. Gunafssor, T. Tholvaldsson, G.L. Dunlop, The influence of $\mathrm{Fe}$ and $\mathrm{Cr}$ on the microstructure of cast Al-Si-Mg alloys, Metal. Trans. A 174 (1986) 45-52.

[30] F.H.SamuelH.R. Ammar, A.M. Samuel, Porosity and the fatigue behavior of hypoeutectic and hypereutectic aluminum-silicon casting alloys, Int. J. Fatigue 30 (2008) 1024-1035.

[31] Z. Li, A.M. Samuel, F.H. Samuel, Effect of alloying elements on the segregation and dissolution of $\mathrm{CuAl}_{2}$ phase in Al-Si-Cu 319 alloys, Mater. Sci. 38 (2003) 1203-1218.

[32] L. Lasa, J.M. Rodrigues-Ibabe, Evolution of the main intermetallic phases in AlSi-Cu-Mg casting alloys during solution treatment, J. Mater. Sci. 39 (2004) 1343-1355.

[33] Y. Awano, Y. Shimini, Non-equilibrium crystallization of AIFeSi compound in melt-superheated Al-Si castings, AFS Trans. 98 (1990) 889-895.

[34] Shivkumar, L. Wang, D. Apelian, Molten metal processing of advanced cast aluminum alloys, J. Met. 43 (1991) 26-31.

[35] R.P. Liu, D.M. Herlach, M. Vandyoussefi, A.L. Greer, Undercooling and solidification of Al-50 at. Pct alloy by electromagnetic levitation, Metall. Mater. Trans. 35A (2004) 7-12.

[36] Anthony C. Fischer-Cripps, Nanoindentation, Springer-Verlag, 2004.

[39] C.L. Chen, A. Richter, R.C. Thomson, Mechanical properties of intermetallic phases in multi-component Al-Si alloys using nanoindentation, Intermetallics 17 (2009) 634-641.

[40] D.J. Skinner, M.S. Zedalis, P. Gilman, Effect of strain rate on tensile ductility for a series of dispersion-strengthened aluminum-based alloys, Mater. Sci. Eng. 119 (1989) 81-86.

[41] D.G. Eskin, L.S. Toropova, Tensile and elastic properties of deformed heterogeneous aluminum-alloys at room and elevated-temperatures, Mater. Sci. Eng. 183 (1994) L1-L4.

[42] L.F. Mondolfo, Aluminum Alloys: Structure and Properties, Butterworth, London, 1976. 